\title{
Correlation Between Serum IGF-1 Levels and CVM Stages for the Assessment of Skeletal Maturity
}

Muhammad Nauman Sadiq ${ }^{1}$

Ahmad Shamim ${ }^{2}$

Muhammad Azeem ${ }^{3}$

Shabbir Hussain ${ }^{4}$

Arfan Ul $\mathrm{Haq}^{5}$

Naeem Murtaza ${ }^{6}$

Waheed UI Hamid ${ }^{7}$

\author{
BDS, MDS \\ BDS, MDS \\ BDS, FCPS \\ BDS, MDS \\ BDS, MDS, FCPS, MCPS \\ BDS, MDS \\ BDS, MOrth, MS, MCPS
}

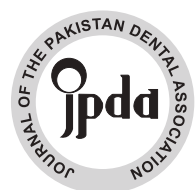

OBJECTIVE: The major disadvantage in cervical vertebral maturation stages (CVMS) is the involvement of radiographic exposure. This study was undertaken to assess the applicability of insulin-like growth factor I (IGF-I) blood level as a maturation indicator by correlating it to the CVMS.

METHODOLOGY: This cross-sectional study was conducted at orthodontic department of our institute. With $80 \%$ power of study, $5 \%$ desired level of significance and using 0.67 correlation value, a sample size of 75 was calculated. There are five stages of CVMS and in each CVM stage 15 subjects were allocated, therefore collective sample size was 75 . The technique of sampling was purposive (non-probability) sampling. Out of 75 patients, $47(62.7 \%)$ were males and $28(37.3 \%)$ were females. The mean ages of the patients were $12.5 \pm 2.6$ years. Analysis of variance (ANOVA) test was performed to evaluate the blood serum IGF-1 levels among five stages of CVMS.

RESULTS: There was a statistically considerable difference in mean IGF-1 among five stages of CVM. The mean IGF- 1 (ng/ml) of CVMS 1 was $204.9 \pm 21.1$, mean IGF-1 of CVMS II was $272.5 \pm 39.5$, mean IGF-1 of CVMS III was 343.1 \pm 38.6 , mean IGF-1 of CVMS IV was $287.7 \pm 22.3$ and mean IGF-1 of CVMS V was $171.5 \pm 24.5$. The highest mean values were observed in stage III followed by stage IV, II, I and V. IGF-1 levels were maximum in females at CVM stage 3 and were maximum in male at CVM 4.

CONCLUSION: IGF-1 levels at the pubertal stage were significantly higher than the pre-pubertal and post-pubertal stages. IGF-1 levels might prove to be a valuable skeletal maturity indicator.

KEY WORDS: Insulin Like Growth Factor-1; IGF-1; Cervical Vertebral Maturational Stages; CVMS.

HOW TO CITE: Sadiq MN, Shamim A, Azeem M, Hussain S, Haq AU, Murtaza N, Hamid WU. Correlation between serum IGF-1 levels and CVM stages for the assessment of skeletal maturity. J Pak Dent Assoc 2020;29(1):9-13.

DOI: https://doi.org/10.25301/JPDA.291.9

Received: 02 July 2019, Accepted: 15 October 2019

\section{INTRODUCTION}

$\mathrm{T}$ he correct treatment planning in orthodontics is significantly dependent on identification of peak growth spurt as growth modification is more effective

1. Specialist/Consultant, Department of Orthodontist, de'Montmorency College of Dentistry, Lahore Pakistan.

2. Assistant Professor, Department of Orthodontics, Azra Naheed Medical \& Dental College, Lahore.

3. Assistant Professor \& Head, Department of Orthodontics Department, Dental College, FMU/PMC, Faisalabad, Pakistan.

4. Assistant Professor, Department of Orthodontics, Rashid Latif Medical \& Dental College, Lahore

5. Professor of Orthodontics, de'Montmorency College of Dentistry, Lahore, Pakistan.

6. Specialist/Consultant, Department of Orthodontist, Dental College-FMU/PMC, Faisalabad, Pakistan.

7. Professor of Orthodontics, de'Montmorency College of Dentistry, Lahore, Pakistan.

Corresponding author: "Dr. Muhammad Azeem" < dental.concepts@ hotmail.com > during rapid pubertal growth spurt period. Profit and Fields suggested that timing difference between boys and girls as girls mature two years earlier as compared to boys. ${ }^{1}$ However, Fishman has revealed that dental age and chronologic age are pitiable interpreters of the pubescent growth spurt. ${ }^{2}$

Various radiographic techniques are in use for skeletal maturation assessment. The most common among these include hand-wrist radiography and cervical vertebral maturation stages (CVMS) through lateral cephalometric radiographs (LCR). ${ }^{3-5}$ The assessment of CVMS is more appealing to orthodontists since LCR are normally in use for orthodontic patients, this method comprises of five distinct stages of anatomic modifications in 2nd (C2), 3rd (C3), and 4th (C4) cervical vertebrae. ${ }^{6,7}$ 
Sadiq MN/ Shamim A/ Azeem M/ Hussain S/ Haq AU/ Murtaza N/ Hamid WU

In recent times, many researchers have studied growth factors like, estrogens, androgens such as testosterone, thyroid hormones, growth hormone, and insulin-like growth factor1(IGF-1). ${ }^{8-10}$ Both local and systemic bone growth regulation is mediated by IGF-1 through growth hormone. ${ }^{11}$

The CVMS method indicates completion of growth at stage V, however, Goto et al., and Mitani et al., showed that some growth still remains. ${ }^{12,13}$ For this reason, there is a need of more reliable biomarker for the skeletal maturity assessment. Chronologic age and sexual maturity stages

co-relation with serum IGF-1 is investigated in the past already. ${ }^{14-16}$ Masoud et al., and Juul A et al., used the bloodspot technique and correlated the IGF-1 levels with CVMS and hand-wrist growth stages. ${ }^{15,17}$

Following this rationale, the objective of this research was to examine and assess different stages of CVMS and then determine serum levels of IGF-1 along with its correlation with different stages of CVMS. Hypothesis was that there is a correlation between serum IGF-1 levels and different stages of CVM.

\section{METHODOLOGY}

Present cross-sectional study was conducted atorthodontic department. Duration of study was one year. With $80 \%$ power of study, $5 \%$ desired level of significance and using 0.67 correlation value, a sample size of 75 was calculated. ${ }^{15}$ There are five stages of CVMS, ${ }^{6,7}$ and in each CVM stage 15 subjects were allocated, therefore collective sample size was 75 . The technique of sampling was purposive (non-probability) sampling.

Following patients were included: patients who were about to begin orthodontic treatment, both genders and age range of 8 to 16 years. Patients with history of systemic illness or bleeding disorder, having growth abnormalities, vertebral issues and syndromic conditions, were excluded.

CVM stages were determined by two blinded expert examiners as per conventional 5 stages method. ${ }^{6,7}$ Five cephalograms were randomly taken from each group, 2 weeks later, to reassess CVM stage to find out interexaminer and intra-examiner reliabilities. For determination of IGF-1 levels, blood samples were taken from the median cubital vein, between $9 \mathrm{am}$ to $10 \mathrm{am}$ on the same day of taking lateral cephalograms, samples were collected in anticoagulant free $\mathrm{BD}$ vacutainer serum tube, were stored in thermocool box with ice cubes (kept between $2^{\circ} \mathrm{C}$ and $8^{\circ} \mathrm{C}$ ), and were centrifuged at $3000 \mathrm{rpm}$. The resulting supernatant was designated serum, which was shifted into $0.5 \mathrm{ml}$ aliquots using Pasteur pipette and stored at -20 C. IGF-1 600 Enzyme Immunoassay Kit (Labor Diagnostika Nord GmbH\& Co. KG) was used for calculation of IGF-1 levels $(\mathrm{ng} / \mathrm{ml})$ in serum samples.
Correlation between serum IGF-1 levels and Skeletal Maturity

\section{DATA ANALYSIS}

The data were analyzed using PASW 18 (Predictive Analytic Software 18). IGF-1 levels (ng/ml), and age variables were presented in form of Mean \pm SD. Data of gender, and CVMS were presented in form of percentages and frequencies. The data were tested for normality by ShapiroWilk test. Comparison between both the genders was also performed. Spearman's correlation test was used to determine the correlation of IGF-1 values at different CVMS. Kappa statistic was used to measure interexaminer and intra-examiner reliabilities in CVM stages determination.

\section{RESULTS}

The mean age of the patients were $12.5 \pm 2.6$ years, out of which $47(62.7 \%)$ were male and 28 (37.3\%) were female. Kappa statistics showed no significant difference in inter-examiner and intra-examiner readings ( 0.88 and 0.89 , respectively).

The mean IGF-1 (ng/ml) of CVMS I was $204.9 \pm 21.1$, mean IGF-1 of CVMS II was $272.5 \pm 39.5$, mean IGF-1 of CVMS III was $343.1 \pm 38.6$, mean IGF- 1 of CVMS IV was $287.7 \pm 22.3$ and mean IGF- 1 of CVMS V was $171.5 \pm 24.5$. The highest mean values were observed in stage III followed by stage IV, II, I and V.

Shapiro Wilk test was used to check the normality of the data. As data was normally distributed, Analysis of variance (ANOVA) test was performed to compare the IGF-1 among five stages of CVM, which revealed that there was a statistically significant difference in mean IGF-1 among 5 CVM stages (Table $1 \& 2$ ).

For multiple comparisons, post hoc Tukey test was used which showed that mean IGF-1 levels at each CVM stage was statistically different from the mean values at the other stages whereas there was no significant difference was found between stage II and IV (Table 3).

Table 1: Descriptive IGF-1 statistics for each Cervical Vertebral Maturation Stage

\begin{tabular}{|c|c|c|c|c|c|}
\hline \multirow{2}{*}{ CVM Stages } & \multirow{2}{*}{$\mathrm{N}$} & \multirow{2}{*}{ Mean \pm SD } & \multirow{2}{*}{ SE } & \multicolumn{2}{|c|}{$95 \%$ CI for Mean } \\
\cline { 5 - 6 } & & & & Lower & Upper \\
\hline CVMS I & 15 & $204.9 \pm 21.1$ & 5.4 & 193.2 & 216.6 \\
\hline CVMS II & 15 & $272.5 \pm 39.5$ & 10.2 & 250.6 & 294.3 \\
\hline CVMS III & 15 & $343.1 \pm 38.6$ & 10.0 & 321.7 & 364.5 \\
\hline CVMS IV & 15 & $287.7 \pm 22.3$ & 5.8 & 275.3 & 300.0 \\
\hline CVMS V & 15 & $171.5 \pm 24.5$ & 6.3 & 158.0 & 185.1 \\
\hline
\end{tabular}


Sadiq MN/ Shamim A/ Azeem M/ Hussain S/ Haq AU/ Murtaza N/ Hamid WU

Table 2: P value (1-way ANOVA)

\begin{tabular}{|c|c|c|c|c|c|}
\hline & Sum of Squares & Df & Mean Square & F & Sig. \\
\hline Between Groups & 279045.511 & 4 & 69761.378 & 75.971 & 0.000 \\
\hline Within Groups & $\mathbf{6 4 2 7 8 . 2 8 5}$ & 70 & 918.261 & & \\
\hline Total & 343323.797 & 74 & & & \\
\hline
\end{tabular}

Table 3: Showing pair wise comparison among groups

\begin{tabular}{|c|c|c|c|c|c|}
\hline \multicolumn{5}{|c|}{ Multiple Comparison } \\
\hline $\begin{array}{c}\text { No. } \\
\text { N. }\end{array}$ & \multicolumn{2}{|c|}{ Groups } & $\begin{array}{c}\text { Mean } \\
\text { Difference }\end{array}$ & SE & p-value \\
\hline \multirow{3}{*}{1} & \multirow{2}{*}{ CVMS I } & CVMS II & $-67.565^{*}$ & 11.065 & 0.000 \\
\cline { 3 - 5 } & & CVMS III & $-138.193^{*}$ & 11.065 & 0.000 \\
\cline { 3 - 5 } & & CVMS V & $33.354^{*}$ & 11.065 & \multirow{2}{*}{0.029} \\
\cline { 3 - 5 } 2 & \multirow{3}{*}{ CVMS II } & CVMS III & $-70.627^{*}$ & 11.065 & 0.000 \\
\cline { 3 - 5 } & & \multirow{2}{*}{ CVMS IV } & -15.203 & 11.065 & 0.646 \\
\cline { 3 - 5 } & & CVMS V & $100.920^{*}$ & 11.065 & 0.000 \\
\hline \multirow{2}{*}{4} & \multirow{2}{*}{ CVMS IV } & CVMS IV & $55.423^{*}$ & 11.065 & 0.000 \\
\cline { 3 - 5 } & & CVMS V & $171.547^{*}$ & 11.065 & 0.000 \\
\hline
\end{tabular}

*The mean difference is significant at the 0.05 level.

Table 4: Showing correlation of CVM Stages with Insulin-Like Growth Factor-1

\begin{tabular}{|c|c|c|c|}
\hline \multicolumn{2}{|c|}{ Spearman's Rho } & $\begin{array}{c}\text { Cervical Vertebral } \\
\text { Maturational Stages } \\
\text { (I - III) }\end{array}$ & $\begin{array}{c}\text { Cervical Vertebral } \\
\text { Maturational Stages } \\
\text { (III - V) }\end{array}$ \\
\hline \multirow{2}{*}{$\begin{array}{c}\text { Insulin-Like } \\
\text { Growth } \\
\text { Factor-1 }\end{array}$} & $\begin{array}{c}\text { Correlation } \\
\text { Coefficient (r) }\end{array}$ & 0.866 & -0.903 \\
\cline { 2 - 4 } & p-value & $<0.001$ & $<0.001$ \\
\cline { 2 - 4 } & $\mathrm{N}$ & 75 & 75 \\
\hline
\end{tabular}

IGF-1 levels were maximum in females at CVM stage 3 and were maximum in male at CVM 4. Significant difference between the IGF-1 levels in males and females was observed at CVMS $2(\mathrm{P}<0.01)$, and $3(\mathrm{P}<0.01)$, while the difference was not significant in other stages. Spearman's Rho correlation test revealed that there was strong positive correlation between IGF-1 level and CVMS I-III and strong negative correlation was observed between IGF-1 and CVMS III-V (Table 4).

\section{DISCUSSION}

The exact knowledge regarding the mandibular developmental stage and remaining total MG is important for orthodontic diagnosis, treatment planning and treatment.
Correlation between serum IGF-1 levels and Skeletal Maturity

This study was designed to check the hypothesis that the blood serum IGF-I level could be used as a skeletal maturity indicator in orthodontics. Physiologically balanced subjects were included in our study because diabetes mellitus and liver diseases have a direct influence on the metabolism of IGF-I and blood serum IGF-1 levels. ${ }^{18,19}$ During the collection of blood samples, we ruled out the patients with bleeding disorders which is according to the study by Masoud et al. ${ }^{15}$

Cervical vertebral maturation techniques were established as the most reliable diagnostic tool. ${ }^{20}$ It was useful in orthodontics as a marker for the status of skeletal maturity. ${ }^{21}$ The CVMS method is proved more advantageous and beneficial as compared to hand-wrist method because of no additional radiation exposure. But the major disadvantage regarding CVMS or hand-wrist method is that radiographically growth is completed, yet mandibular growth remains. ${ }^{12,13}$ For this reason other methods of biologic maturity assessment are needed along with CVMS stages, when considering any procedure regarding orthognathic surgery or dentofacial orthopedic treatment. ${ }^{22}$ There are lot of methods are available for cervical vertebral maturation, in our research, CVMS method as described by Baccetti et al., was used. ${ }^{6}$

In the present study blood samples were taken to find out the serum IGF-1 levels. In different studies saliva, gingival crevicular fluid, and urine were used as non invasive sources for the estimation of IGF-1. ${ }^{23-25}$ In case of urinary IGF-1, patient cooperation is a major factor, because sample collection without contamination is very difficult especially for patient. ${ }^{25}$

In the present study the IGF-I evaluation was perform with ELISA Kit because of simplicity of this procedure and it was supported by other investigators. ${ }^{26,27}$ Other investigators adopted different techniques such as immunoradiometric assays and radioimmunoassays. ${ }^{15,28}$ Studies showed that all assays techniques were comparatively précised and accurate when performed in physically fit persons. ${ }^{29}$

Results showed that the highest mean values were observed in stage III followed by stage IV, II, I and V. At CVMS III blood serum IGF-I levels were at peak with a signify value of $343.05 \mathrm{ng} / \mathrm{mL}$, and these peak levels can be linked with upcoming pubertal growth spurt, and residual mandibular growth. ${ }^{15,28,20}$ Differences in results from other studies can be attributed to difference of chronological age for peak IGF-1 levels. Differences might also be due to the disparity in inclusion criteria, racial backgrounds, genetic factors, environmental factors, and the technique adopted for this study.

In the present study blood serum IGF-1 levels were maximum in females at CVM stage 3 and were maximum in male at CVM 4. This is in agreement with the various previous studies where such similar rise was seen for both 
males and females. ${ }^{8,10,31-33}$ But findings are in contrast with findings of Masoud et al. who showed that peak IGF-1 values were at CVM stage 5 for both the genders. ${ }^{15}$

Results showed that in girls blood serum IGF-1 levels rise from CVMS I to rapid increase seen from CVMS I to peak at CVMS III, followed by a rapid reduction from CVMS III to CVMS IV continuing to CVMS V; whereas in boys there was a stable raise in IGF-1 levels from CVMS I to CVMS IV, which steadily spiky at CVMS IV follow by a sluggish decline to CVMS V. These results reconfirm prior studies signifying that female subjects have a shorter and earlier growth burst denote by sharp rise and sharp fall in IGF-1 levels, while in boys, there is a later and longer growth spurt. ${ }^{34}$

In the present study a marked positive relationship was observed between IGF-1 levels and CVMS stages from prepubertal phase (CVMS I) to pubertal phase(CVMS III), whereas there was a negative correlation between IGF-1 levels and CVMS IV and CVMS V stages that is from pubertal phase to postpubertal phase. Our study's results matched with previous studies that show blood serum IGF-1 peak in early puberty followed by a decrease in late puberty. ${ }^{35,36}$

\section{CONCLUSION}

IGF-1 levels at the pubertal stage were significantly higher than the pre-pubertal and post-pubertal stages. IGF1 levels might prove to be a valuable skeletal maturity indicator.

\section{CONFLICT OF INTEREST}

None declared

\section{REFERENCES}

1. Proffit WR. The timing of early treatment: an overview. Am J Orthod Dentofac Orthop. 2006;129:S47-9.

https://doi.org/10.1016/j.ajodo.2005.09.014

2. Fishman LS. Radiographic evaluation of skeletal maturation: a clinically oriented method based on hand-wrist films. Angle Orthod. 1982;52:88-112.

3. Szemraj A, Wojtaszek-Slominska A, Racka-Pilszak B. Is the cervical vertebral maturation $(\mathrm{CVM})$ method effective enough to replace the hand-wrist maturation (HWM) method in determining skeletal maturation?-A systematic review. Europ J Radiol. 2018;102:125-28. https://doi.org/10.1016/j.ejrad.2018.03.012

4. McNamara Jr JA, Franchi L. The cervical vertebral maturation method: A user's guide. Angle Orthod. 2018;88:133-43.

https://doi.org/10.2319/111517-787.1
5. Engel TP, Renkema AM, Katsaros C, Pazera P, Pandis N, Fudalej PS. The cervical vertebrae maturation (CVM) method cannot predict craniofacial growth in girls with Class II malocclusion. Europ J Orthod. 2015;38:1-7.

https://doi.org/10.1093/ejo/cju085

6. Baccetti T, Franchi L, McNamara JA Jr. The Cervical Vertebral Maturation (CVM) method for the assessment of optimal treatment timing in dentofacial orthopedics. Semin Orthod. 2005;11:119-29. https://doi.org/10.1053/j.sodo.2005.04.005

7. Lamparski DG, Nanda SK. Skeletal age assessment utilizing cervical vertebrae. In: JA McNamara Jr, Kelly KA, eds. Treatment Timing: Orthodontics in Four Dimensions. Ann Arbor, Mich: Monograph 39, Craniofacial Growth Series, Department of Orthodontics and Pediatric Dentistry and Center for Human Growth and Development, University of Michigan; 2002.

8. Jain N, Tripathi T, Gupta SK, Rai P, Kanase A, Kalra S. Serum IGF-1, IGFBP-3 and their ratio: potential biochemical growth maturity indicators. Progress Orthod. 2017;18:11.

https://doi.org/10.1186/s40510-017-0165-1

9. Mehta S. Serum and urine insulin-like growth factor-1 as biochemical growth maturity indicators. Am J Orthod Dentofac Orthop. 2017 151:836.

https://doi.org/10.1016/j.ajodo.2017.02.005

10. Gupta S, Deoskar A, Gupta P, Jain S. Serum insulin-like growth factor-1 levels in females and males in different cervical vertebral maturation stages. Dental Press J Orthod. 2015;20:68-75.

https://doi.org/10.1590/2176-9451.20.2.068-075.oar

11. Yakar S, Rosen CJ, Beamer WG, Ackert-Bicknell CL, Wu Y, Liu JL, Ooi GT, Setser J, Frystyk J, Boisclair YR, LeRoith D. Circulating levels of IGF-1 directly regulate bone growth and density. J Clin Invest. 2002;110:771-81.

https://doi.org/10.1172/JC10215463

12. Goto S, Kondo T, Negoro T, Boyd RL, Nielsen L, Iizuka T. Ossification of the distal phalanx of the first digit as a maturity indicator for initiation of orthodontic treatment of Class III malocclusion in Japanese women. Am J Orthod Dentofac Orthop.1996;110:490-501. https://doi.org/10.1016/S0889-5406(96)70055-0

13. Mitani H, Sato K, Sugawara J. Growth of mandibular prognathism after pubertal growth peak. Am J Orthod Dentofac Orthop. 1993;104:330-36.

https://doi.org/10.1016/S0889-5406(05)81329-0

14. Masoud MI, Marghalani HY, Masoud IM, Gowharji NF. Prospective longitudinal evaluation of the relationship between changes in mandibular length and blood-spot IGF-1 measurements. Am J Orthod Dentofac Orthop 2012;141:694-704.

https://doi.org/10.1016/j.ajodo.2011.12.021

15. Masoud M, Masoud I, Kent Jr RL, Gowharji N, Cohen LE. Assessing skeletal maturity by using blood spot insulin-like growth factor I (IGF-I) testing. Am J Orthod Dentofac Orthop. 2008;134:20916.

https://doi.org/10.1016/j.ajodo.2006.09.063 
16. Masoud MI, Masoud I, Kent Jr RL, Gowharji N, Hassan AH, Cohen LE. Relationship between blood-spot insulin-like growth factor 1 levels and hand-wrist assessment of skeletal maturity. Am J Orthod Dentofac Orthop. 2009;136:59-64.

https://doi.org/10.1016/j.ajodo.2007.07.023

17. Juul A, Holm K, Kastrup KW, Pedersen SA, Michaelsen KF, Scheike T, Rasmussen S, Mu“ller J, Skakkebæk NE. Free insulin-like growth factor I serum levels in 1430 healthy children and adults, and its diagnostic value in patients suspected of growth hormone deficiency. J Clin Endocrinol Metabolism. 1997;82:2497-502.

https://doi.org/10.1210/jcem.82.8.4137

18. Froesch ER, Hussain MA, Schmid C, Zapf J. Insulin-like growth factor I: physiology, metabolic effects and clinical uses. Diabetes/Metabolism Rev. 1996;12:195-215.

https://doi.org/10.1002/(SICI)1099-0895(199610)12:3<195::AIDDMR164>3.0.CO;2-G

19. Žofková I. Pathophysiological and clinical importance of insulinlike growth factor-I with respect to bone metabolism. Physiol Res. 2003;52:657-79.

20. Hosni S, Burnside G, Watkinson S, Harrison JE. Comparison of statural height growth velocity at different cervical vertebral maturation stages. Am J Orthod Dentofac Orthop. 2018;154:545-53.

https://doi.org/10.1016/j.ajodo.2017.12.016

21. Franchi L, McNamara JA. Validity of the CVM method to determine mandibular length. Am J Orthod Dentofac Orthop. 2016;150:6-7. https://doi.org/10.1016/j.ajodo.2016.04.014

22. Ball G, Woodside D, Tompson B, Hunter WS, Posluns J. Relationship between cervical vertebral maturation and mandibular growth. Am J Orthod Dentofac Orthop. 2011;139:e455-61. https://doi.org/10.1016/j.ajodo.2010.01.035

23. Gaur A, Maheshwari S, Verma SK. Detection of molecular biomarkers as a diagnostic tool in the planning and progression of orthodontic treatment. J Orofac Sci. 2017;9:80.

https://doi.org/10.4103/jofs.jofs_98_16

24. Alhadlaq AM, Patil S. Biomarkers of orthodontic tooth movement in gingival crevicular fluid: a systematic review. J Contemp Dent Pract. 2015;16:578-87.

https://doi.org/10.5005/jp-journals-10024-1725

25. Sinha M, Tripathi T, Rai P, Gupta SK. Serum and urine insulinlike growth factor-1 as biochemical growth maturity indicators. Am J Orthod Dentofac Orthop. 2016;150:1020-7.

https://doi.org/10.1016/j.ajodo.2016.04.028

26. Byrne C, Colditz GA, Willett WC, Speizer FE, Pollak M, Hankinson SE. Plasma insulin-like growth factor (IGF) I, IGF-binding protein 3, and Mammographic Density. Cancer Res. 2000;60:3744-8.
27. Zumbado M, Luzardo OP, Lara PC, Álvarez-León EE, Losada A, Apolinario R, Serra-Majem L, Boada LD. Insulin-like growth factorI (IGF-I) serum concentrations in healthy children and adolescents: relationship to level of contamination by DDT-derivative pesticides. Growth Hormone IGF Res. 2010;20:63-7. https://doi.org/10.1016/j.ghir.2009.07.003

28. Kanbur NÖ, Derman O, Kinik E. The relationships between pubertal development, IGF-1 axis, and bone formation in healthy adolescents. J Bone Mineral Metabolism. 2005;23:76-83.

https://doi.org/10.1007/s00774-004-0544-9

29. Franchi L, Baccetti T, McNamara Jr JA. Mandibular growth as related to cervical vertebral maturation and body height. Am J Orthod Dentofac Orthop. 2000;118:335-40.

https://doi.org/10.1067/mod.2000.107009

30. Baquedano MS, Berensztein E, Saraco N, Dorn GV, De Davila MT, Rivarola MA, Belgorosky A. Expression of the IGF system in human adrenal tissues from early infancy to late puberty: implications for the development of adrenarche. Pediatr Res. $2005 ; 58: 451$.

https://doi.org/10.1203/01.PDR.0000179392.59060.93

31. Ishaq RA, Soliman SA, Foda MY, Fayed MM. Insulin-like growth factor 1: a biologic maturation indicator. Am J Orthod Dentofac Orthop. 2012;142:654-61.

https://doi.org/10.1016/j.ajodo.2012.06.015

32. Jain S, Jain S, Deoskar A, Prasad VS. Serum IGF-1 levels as a clinical tool for optimizing orthodontic treatment timing. Prog Orthod. 2013;14:46.

https://doi.org/10.1186/2196-1042-14-46

33. Ratcliffe SG, Masera N, Skinner AM, Jones J, Morrell D, Pan H, et al. Urinary insulin-like-growth factor 1 in normal children: relationship to age, pubertal status and urinary growth hormone. Growth Regul. 1995;5:53-9.

34. Hägg U, Taranger J. Maturation indicators and the pubertal growth spurt. Am J Orthod.1982;82:299-309.

https://doi.org/10.1016/0002-9416(82)90464-X

35. Chatzigianni A, Halazonetis DJ. Geometric morphometric evaluation of cervical vertebrae shape and its relationship to skeletal maturation. Am J Orthod Dentofac Orthop. 2009;136:481-e1.

https://doi.org/10.1016/j.ajodo.2009.04.017

36. Lo "fqvist C, Andersson E, Gelander L, Rosberg S, Blum WF, Wikland KA. Reference values for IGF-I throughout childhood and adolescence: a model that accounts simultaneously for the effect of gender, age, and puberty. J Clin Endocrinol Metabolism. 2001;86:587076.

https://doi.org/10.1210/jcem.86.12.8117 